\title{
DEVELOPMENT OF ANTARCTIC TOURISM
}

\author{
Tadeusz PALMOWSKI*
}

University of Gdańsk, Department Regional Development,

Instytut Geografii, ul. Bażyńskiego 4, 80-309 Gdańsk, Poland, e-mail: tadeusz.palmowski@ug.edu.pl

Citation: Palmowski, T. (2020). DEVELOPMENT OF ANTARCTIC TOURISM. GeoJournal of Tourism and Geosites, 33(4spl), 1520-1526. https://doi.org/10.30892/gtg.334spl11-602

\begin{abstract}
According to some specialists, Antarctic tourism is one of the best-managed tourism sectors in the world. It has dynamically developed in recent decades. Starting the second half of the eighties of the twentieth century, tourist figures in Antarctica grew exponentially from several hundred to 74 thousand annually. The seasonal and spatial restrictions mark its specific nature. The author believes in the need for comprehensive control of tourist activity and behaviour on the continent. The International Association of Antarctica Tour Operators (IATTO) promotes safe and environmentally responsible voyages to Antarctica. Education is vital during these visits, providing an opportunity to become acquainted with this exceptional continent and its merit for world science. Tourists, representing over 100 nationalities, become the ambassadors of Antarctica on returning home. Study results indicate that immoderate development of Antarctic tourism may generate threats and the introduction of related restrictions.
\end{abstract}

Key words: Antarctic tourism, polar tourism, tourism development, Antarctic Treaty System, IAATO.

$* * * * * *$

\section{INTRODUCTION}

Antarctica embraces the continent itself and surrounding waters. The name itself conjures up visions of mountains with flowing glaciers, menacing seas sprinkled with icebergs and animals not to be met elsewhere. This most elevated continent covers approximately one tenths of the planets land surface, nearly $90 \%$ of ice on Earth and about $70 \%$ of its fresh water resources.

Historically, humankind presence in and near Antarctica started rather late and was strictly related to the development of knowledge and technology required to gain access to this far distanced continent on the globe. In the past, human presence was predominantly associated with the exploitation of natural resources such as seals and whales. It also involved scientific research at an early stage of exploration. Oncoming phases focused on fishing fin and krill in the Southern Ocean waters, and the development of tourism.

Thirty countries, which signed the Antarctic Treaty, established here over seventy permanent and seasonal research stations by 2017 (Antarctic Station Catalogue, 2017). Annually, they host around four thousand researchers in the summer season and eleven hundred in wintertime. Scientists conduct research on the continent and in adjacent sea basins.

As the Antarctica continent has become the subject of interest for humankind in general, it attracts a growing number of people who wish to see it. At present, the main field of economic activity in Antarctica is the dynamically developing tourism (Stewart et al., 2010).

The shortage of comprehensive studies at the end of the second decade of the twenty first century stimulated the author to fill in this gap and focus on assessing tourism operations on the continent. Thus, the author put forward the following question: how does the growing Antarctic tourism influence this unique continent? Environmental monitoring shows the need for comprehensive control of tourist activity and behaviour on the continent. The question fits well into the study discourse on Antarctic marine tourism (Engelbertz et al., 2015; Johnston, 1997). The growing number of ships, and consequently tourists, may prompt the adoption of a stricter regime for particular locations, towards apposite guided and flexible marine tourism regulations (Liggett and Storey, 2007; Haase et al., 2007).

From the start, at the end of the fifties of the twentieth century, both the scope and variety of visits continue to expand. The International Association of Antarctica Tour Operators (IAATO), established here in 1991, assists the tourist sector (Enzenbacher, 1993). The objective of the Association is to support and promote safe, environmentally friendly and responsible trips to Antarctica. Thousands of tourists have experienced this natural miracle continent leaving minor or no footprint of their presence since that time. The overall number of tourists visiting Antarctica increased from 2.5 thousand in the years 1990-1991 to over 46 thousand in the 2007-2008 season and 74 thousand in 2019-2020 (IAATO, 2019c). The demand for other kinds of adventure voyages such as hiking, mountaineering, bird watching, photography tours, which are serviced by the aviation industry, continue to grow besides the demand for traditional cruises and excursions by ship. The physical isolation of Antarctica, the extreme climate and the exceptional assets of the natural environment are a significant part of its tourist appeal. The major attraction of these far distanced areas is their primeval character, untouched natural environment, exceptional and unique landscape. All the above works like a magnet attracting more tourists. Those wish to find the last desert on the Earth's surface, the last frontier on the planet, to feel like former discoverers, such as Shackelton, Mawson, Amundsen and Scott. They wish to experience the iciness, isolation and mysticism of this remote place, reckless seas, mountain scenery and tall ice peaks. They wish to come across wild nature; penguins, seabirds, seals and whales. The characteristic feature of Antarctica tourism is its spatial restrictions. Navigation closer to shore and landings are limited to several ice-free areas, which cover less than $0.5 \%$ of the continent's total surface. Most of them cluster on the coast of the Antarctic Peninsula. Antarctic tourism is seasonal and limited to four Antarctic summer months: from November to February.

\section{MATERIALS AND METHODS}

The article draws on recent Antarctic tourism studies, IAATO documents, predominantly from the years 2018 and 2019 , containing statistical data and own observations. The collected scientific data about Antarctica resort to several disciplines; including environmental science, geography, law and economics. Data also come from studies of expert organisations. The analysis of professional literature and source materials, a structured and systematic approach to the data as well as the analysis of the structure and dynamics of tourist traffic as per country, visited locations, kinds and forms of practiced tourism, by applying simple statistic methodology, verified the thesis set in the article and answered the research question. The conducted study fits into the ongoing discussion on the present and future of Antarctic tourism. A

\footnotetext{
${ }^{*}$ Corresponding author
} 
series of lectures and discussions conducted by experts specialising in various fields in many scientific centres, during a cruise on board the modern hybrid vessel Roald Amundsen of the Norwegian shipowner Hurtigruten at the end of 2019, inspired me to undertake this theme.

\section{HISTORY OF ANTARCTIC TOURISM}

In the twenties of the twentieth century, a postal vessel SS „Fleurus” sailed annually from the Falkland Islands to South Shetland Islands and South Orkney Islands to provide services to whaling stations and seal hunters. The ship also carried a small number of commercial passengers, who acquired 'tourist tickets' both ways. These were probably the first commercial tourists who sailed to Antarctica. The next stage of Antarctic tourism dates back to the fifties of the twentieth century, when Chilean and Argentinean transport vessels began to take on board passengers to the South Shetland Islands. Jointly, they took on board over 500 passengers.

The concept of 'exploration voyages' linked with an educational profile started in 1966 when Lars-Eric Lindblad (from Lindblad Travel, New York) chartered an Argentinean vessel 'Lapataia' and accompanied by a group of tourists from South America sailed a thousand kilometres to South Shetland Islands through the stormy waters of Drake's Passage (Liggett, 2015). The following stage of expedition type cruises started in 1969 when Lindblad built 'Lindblad Explorer', the first exploration ship designed to carry passengers to Antarctica (Headland, 2009). A further step in developing marine tourism took place following the disintegration of the Soviet Union, when icestrengthened ships and icebreakers of the former Soviet navy became available for charter to companies organising Antarctic cruises (Molenaar, 2005; Landau and Splettstoesser, 2007; Snyder and Stonehouse, 2007).

The Antarctica aviation tourist sector, offering a bird's view, initiated flights in 1959, when the operator of Linea Aerea Nacional took 66 passengers flying from Chilli over the South Shetland Islands (Tourism and Non-Governmental Activities, 2012.) In 1957, Pan Am airlines performed the first commercial tourist flight to the continental part of Antarctica flying from Christchurch to McMurdo Sound (Headland, 2009). Former activity of man in Antarctica was limited to the first discoverers, those who sought luck in exploiting seals and whales, and recently to those pursuing scientific research and exploration. The majority of tourist expeditions to Antarctica is by sea and remain in line with an environmentally friendly model of behaviour set down initially by Lars Erica and Lindblad. By the end of the eighties of the twentieth century, four companies dealt with ship cruises to Antarctica and one land operator who was a pioneer in commercial tourist flights to the continent. These flights transported guests inland for seasonal field camps, hikes with a guide, ski expeditions and other type of adventure expeditions (Antarctic Flights, 2020). Sailing and motor yachts started reaching Antarctica in the sixties of the twentieth century.

\section{Directions and forms of Antarctic tourism}

Antarctica is an exceptional place with no hotels on land, no local markets. Shopping is limited to several souvenir shops at research stations of some countries. The summer season, when sightseeing is possible, falls between November and March. For the rest of the year dense sea ice surrounds the continent barring ships and tourist landings. Vessels sailing in the region of the Antarctic Peninsula usually set off from Ushuaia (Argentina), Port Stanley (Falkland Islands) or less often from Punta Arenas (Chilli), Buenos Aires (Argentina) and Puerto Madryn (Argentina). Additionally, several expeditions provide cruises in the Ross Sea region and east Antarctica setting out from Bluff and Lyttelton-Christchurch (New Zeeland) or Hobart (Australia) and less often from Cape Town and Port Elizabeth (Republic of South Africa) and Fremantle (Australia). Marine tourism in Antarctica is presently spreading in many directions and extends, apart from the traditional west and part of the southern and eastern part, to the Queen Maud Land situated in the continent's northern part.

The specifics of Antarctica tourism also involve its spatial restrictions. Due to the distance and navigation options, landing is restricted to several ice-free areas (less than $0.5 \%$ of the total area of the continent), most centred on the coast of the Antarctica Peninsula (Figure 1). Apart from better access, the region enjoys a milder climate compared to other part of Antarctica. Concurrently, this area converges land ecosystems, seals and seabirds. The region is particularly interesting for tourists because it offers a unique opportunity to admire and document the wild nature of Antarctica. It also gives the option of visiting research stations concerted in this region (Neumann, 2020).

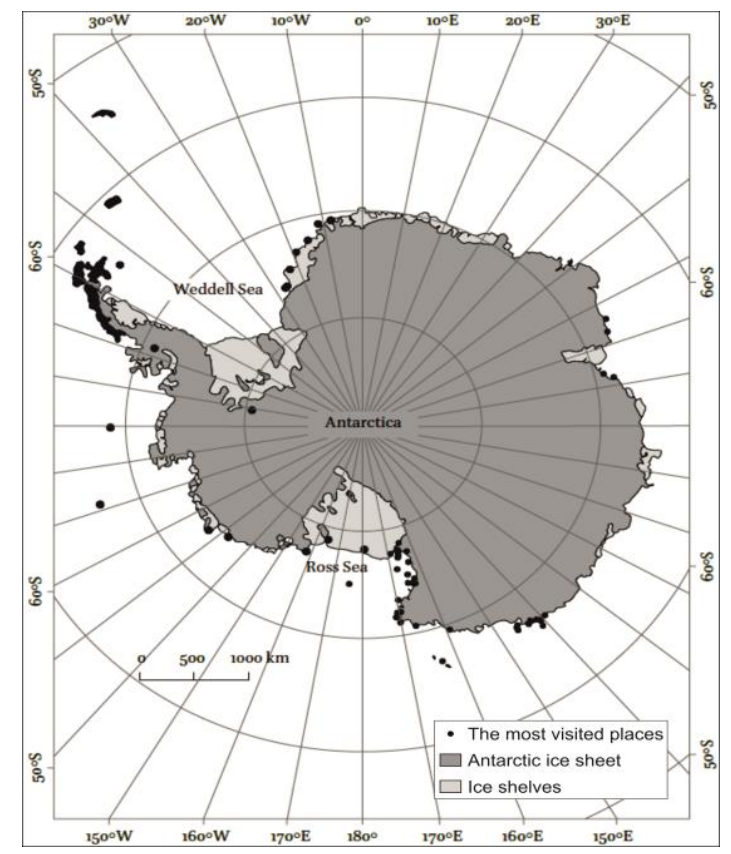

Figure 1. Antarctica locations most often visited by tourists (Source: Neuman, 2020.p 234; supplemented)

Flying in the Ross Sea region is an alternative to sea voyages organised by Croydon Travel from Melbourne assisted by Qantas. Some adventuresome tourists fly inland to seasonal field camps for ski expeditions with a guide (Table 1). They also participate in polar expeditions and climb the highest peak of the continent Vinson Massif, 4897 m, or ski to the South Pole provided by Adventure Network International (ANI). 
Most landings on shore are serviced by pontoon boats (Zodiac, Polar Cirkel Boat, RIB, Naiad, etc.), and over $90 \%$ of tourist activity focuses in the Antarctica Peninsula region and coastal islands west of the peninsula. The geographical spread of tourist activity in the Antarctica Peninsula region, according to IAATO (2018), can be broken down to several sub regions (Table 2).

- South Orkneys Including Laurie, Coronation Islands;

- Elephant Island including nearby islands;

- The South Shetland Islands Including Deception, Livingston, King George, Low and Smith Islands;

- Northeast Antarctic Peninsula from Cape Dubouzet (63 16'S, 57 03'W) to James Ross Island;

- Northwest Antarctic Peninsula from Cape Dubouzet (63 16'S, 57 03'W) to the north end of Lemaire Channel;

- Southwest Antarctic Peninsula from the north end of Lemaire Channel to the area of Marguerite Bay (67 34'S) (Cavallo, 2019).

Table 1. Programs and Participant Numbers (clients) for the 2018-19 season (note some participants may take part in several programs) (Source: IAATO 2019c, p.4)

\begin{tabular}{|c|c|}
\hline Programme & No. Participating \\
\hline Emperor Penguin Colony Visits & 142 \\
\hline $\begin{array}{c}\text { Deep Field Experiences (Camping, skiing, } \\
\text { mountaineering, skydiving, cycling, etc.) }\end{array}$ & 44 \\
\hline Deep Field Flights (e.g. to Pole of Inaccessibility) & 17 \\
\hline South Pole Fly-in & 172 \\
\hline South Pole Ski Expedition & 14 \\
\hline South Pole Motorised Expedition & 22 \\
\hline Last 1-2 Degree Expedition & 43 \\
\hline Antarctic Crossing & 3 \\
\hline Vinson Massif & 148 \\
\hline Marathon & 110 \\
\hline
\end{tabular}

Legal and organisational regulations governing tourism in Antarctica

In 1959, the governments of Argentina, Australia, Belgium, Chilli, France, Japan, New Zealand, Norway, Republic of South Africa, Russia, Great Britain and the United States signed the Antarctic Treaty System (ATS). Thanks to the Treaty, Antarctica became a scientific preserve, for scientific investigation and research. The Antarctic Treaty (1959) states that the continent "...shall be used for peaceful purposes only." and promotes peaceful scientific investigation and international exchange of research results obtained on the continent. The Treaty embraces the area south of $60^{\circ} \mathrm{S}$ latitude in the southern hemisphere.

When in 1961 the Treaty entered into force, it did not refer to tourism. At the time, it was not obvious that a considerable number of tourists would wish to visit the location visited by scientists under expeditions sponsored by governments. In view of the developing tourism, the Treaty Parties adopted a number of recommendations, which influenced the tourism sector. In 1991, Parties to the Antarctic Treaty adopted the Protocol on Environmental Protection to the Antarctic Treaty (Madrid Protocol). The Protocol assures comprehensive protection of Antarctic environment and dependent and associated ecosystems, as a natural reserve dedicated to peace and science.

Nevertheless, the Madrid Protocol came into force as late as 1998, but introduced a comprehensive and systematic management system, which referred predominantly to tourism. Under the protocol, all forms of human activity are subject to environmental assessment, and all actions likely to have more than a minor or transitory impact require an environmental assessment. The Protocol applies under varied legal means in particular signatory countries. By 2018, 53 countries joined ATS. Tourists visiting Antarctica fall under the law of their country during their stay in the region (provided the country is a party to ATS). To prevent the detrimental impact of tourism on the Antarctic environment, trip organisers established the International Association of Antarctica Tour Operators (IATTO) in 1991. The objective of the Association is to promote safe and environmentally responsible ventures to Antarctica (Splettstoesser, 2000; Haase et al., 2009).

IAATO is an international body comprising over one hundred companies from Argentina, Australia, Belgium, Canada, Chilli, France, Germany, Italy, Japan, the Netherlands, New Zealand, Norway, People's Republic of China, Russia, South Africa, Sweden, Switzerland, Great Britain, the United States, and overseas territories such as Falkland Islands (Malvinas). Members include ship operators, ship agents, tourist bureaus, governmental bodies, travel bureaus chartering ships and planes from operators, environmental protection organisations and expedition management companies. In order to promote safe and environmentally friendly measures, IAATO members developed and set detailed operational procedures and guidelines including regulations and restrictions as to the number of persons on land at a time. They also worked out guidelines on selecting exact locations, activities and nature observing as well as reporting requirements of these activities prior and following the visit, briefings for passengers, crew and personnel, proportion of passengers to personnel. Further guidelines refer to cleaning shoes and preventing the introduction of non-native species, signs on ice deserts, schedules and communication procedures with ships, medical evacuation procedures in emergencies, contingency plans, guidelines for watching marine fauna, principles governing station visits and many others. Apart from preparing guidelines for safe and responsible tourism, IATTO set up a code of proceeding for tourists, which was modified by Parties to the Treaty, that gave grounds for Recommendations XVIII-I, which include the Guidance for Visitors to the Antarctic and Guidance for those Organising and Conducting Tourism and Non-Governmental Activities in the Antarctic.

Tourists on board vessels of all IAATO Member States participate in mandatory lectures to become familiar with the code of proceedings during visits on land. They learn about the minimum distance to be kept between people and the wild fauna and flora, that there are no toilets in landing locations and that no food or beverages can be taken on land, and that smoking is strictly forbidden.

In order to raise public awareness and care to preserve the Antarctic environment IATTO cooperates with ATS Parties, the mass media and environmental organisations. Member companies provide logistic and scientific support for national programs and Antarctic organisations. Antarctic cruisers carry over a hundred scientists every polar season. They also transport equipment and supplies to research stations and camps. In the summer season 2018 - 2019, IAATO operators provided assistance 133 times. Ships are also chartered under national Antarctic programmes before and after the cruising season. Trip organisers and passengers contribute financially to scientific organisations operating in Antarctica and their efforts to protect its environment. The key organisations are: Save the Albatross, UK Antarctic Heritage Trust, NZ Antarctic Heritage Trust, South Georgia Heritage Trust, Last Ocean, Mawson's Huts Foundation, World 
Wildlife Fund i College of the Atlantic's Humpback Whale Identification Project. The IAATO global network associates over 100 members, including 47 tourism operators in 2019. IAATO associated 87 ships broken down to four different categories:

- C1: category 1 (vessels carrying 13 to 200 passengers);

- $\mathrm{C} 1$ : category 2 (vessels carrying 201 to 500 passengers);

- CR: only cruises (vessels carrying over 500 passengers);

- YA: Yachts (up to 12 passengers).

Cruises on small and medium sized vessels (C1, C2), (Figure 2, Figure 3), apart from landings on small boats also provide attractions like: kayaking, mountaineering, running events, SCUBA diving, snorkelling, swimming, skiing, snowboarding, snowshoeing, stand-up paddle boarding, camping (including short overnight stays) and helicopter operations (IAATO 2019a).

Traditional expedition cruises are complement now by large cruiser trips (CR) carrying over 500 passengers reaching even 3 thousand guests. Their passengers may admire Antarctic landscapes from ship decks but may not go on land. Voyages on board sailing and motor yachts (YA) are another developing form of travelling to Antarctica.

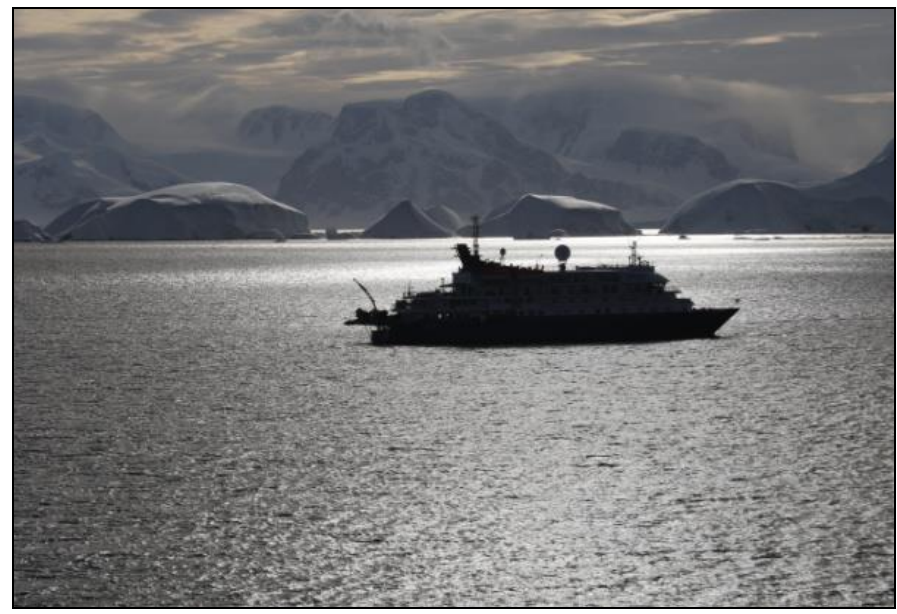

Figure 2. The vessel National Geographic Explorer by the Antarctic coast

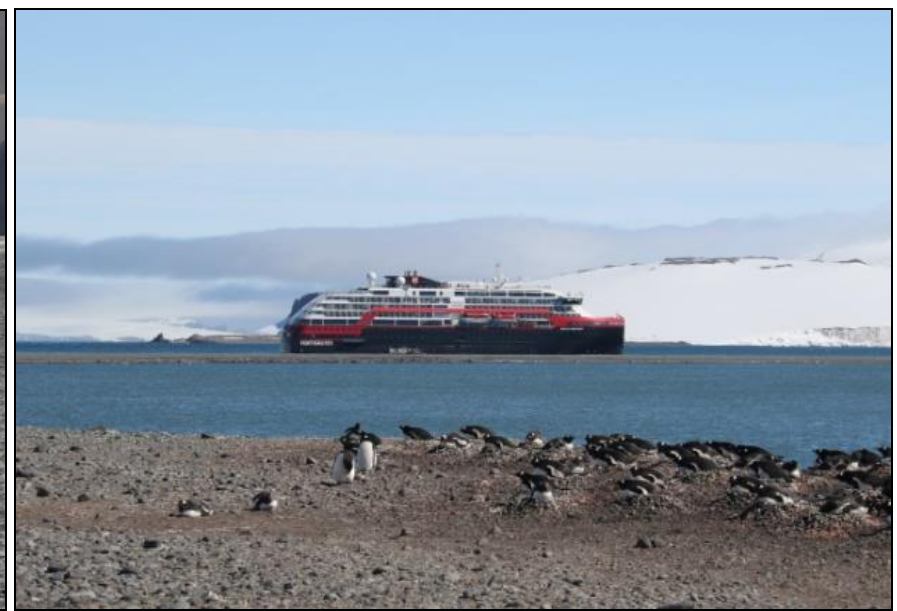

Figure 3. Roald Amundsen by South Shetland Islands

In order to improve navigation in the Antarctic region, where taking measurements is difficult and expensive, IAATO participates in crowd sourcing and transfers bathymetric data to hydrograph centres, including the International Hydrographic Organisation (IHO).

Thanks to IAATO, many Antarctic visitors can participate in citizenship learning and practical involvement in scientific projects. It is a powerful instrument developing scientific knowledge, social involvement and education (IAATO, 2019b).

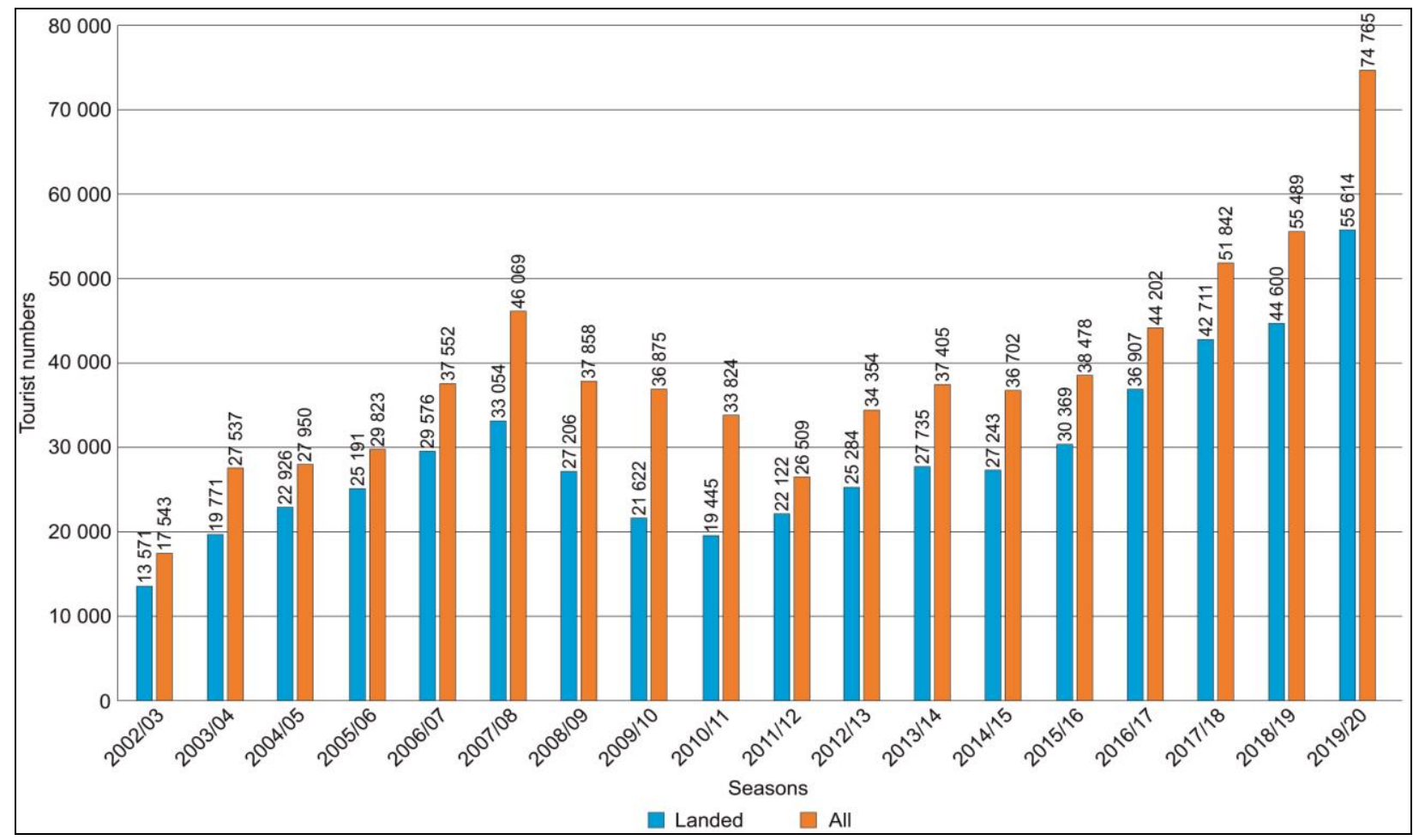

Figure 4. Development of Antarctic tourist numbers from 2002/2003 until 2019/2020 (Source: IAATO, 2019c, p.3; IAATO, 2020; supplemented)

\section{Antarctic tourism in figures}

Starting the end of the fifties in the twentieth century, the first flight and cruise, organised from Argentina and Chilli, launched commercial Antarctic tourism. Since then, the number of tourists gradually grows especially in terms of tourist excursions. In the seventies, 
there was only one operator, who developed a model for travelling to Antarctica - ship cruises also called the 'Lindblad model' (Enzenbacher, 1993). The growing ship capacity contributed to the increasing number of Antarctic tourists. The summer seasons 1974/75, and later 1985/86 and 1990/91 evidenced the above. By the 1991/92 season, when IAATO was established, circa 6.4 thousand tourists visited Antarctica travelling on board ten excursion vessels of six operators, serviced on land by one land operator. The increased number of cruisers and chartered vessels was connected with former USSR ships entering this market. The number of tourists continued to grow and at the turn of the millennium it reached 10 thousand. The next record, of over 46 thousand, was linked with the IV International Polar Year in the $2007 / 2008$ season, next followed by a drop resulting from the global economic downturn. The sector revived after 2011 and reached nearly 56 thousand visitors in the years 2018-2019, exceeding 74 thousand in 2019/2020 (Figure 4), (IAATO, 2019c; IAATO, 2020).

Among the 100 visiting nationalities, the majority of tourists come from The United States. At the turn of the millennium, US citizens constituted more than half of Antarctic visitors. This correlates with the fact that a number of large IAATO member ships belong to tour operators from the USA. China ranks second before Australia and traditional tourist leaders like Germany and Great Britain (Table 3). The share of Central and Eastern Europe is sporadic. Social and economic factors affect the origin of Antarctic visitors.

Table 3. Visitors by nationality 2018-2019 Seaborne, Airborne, Landed and Cruise (Sources: IAATO, 2019c, p.5.)

\begin{tabular}{|l|c|c|}
\hline Country of Origin & Numbers & Percentage \\
\hline United States & 18942 & 34.1 \\
\hline China & 8149 & 14.7 \\
\hline Australia & 5077 & 6.3 \\
\hline Germany & 3491 & 7.6 \\
\hline United Kingdom & 4221 & 3.8 \\
\hline France & 2121 & 4.7 \\
\hline Canada & 2627 & 1.8 \\
\hline Switzerland & 1051 & 15.4 \\
\hline Others & 8518 & 100 \\
\hline Totals & 36907 & \\
\hline
\end{tabular}

Nearly all visitors travelling to Antarctica with IAATO operators came by sea from Chilli or Argentina (Figure 5). A limited number set out from New Zealand or Australia. Some flew in from South America to Antarctic Peninsula and embarked on board ships to continue their journey. Approximately $1 \%$ of all visitors flew in from South America and South Africa to reach field camps and see inland Antarctica.

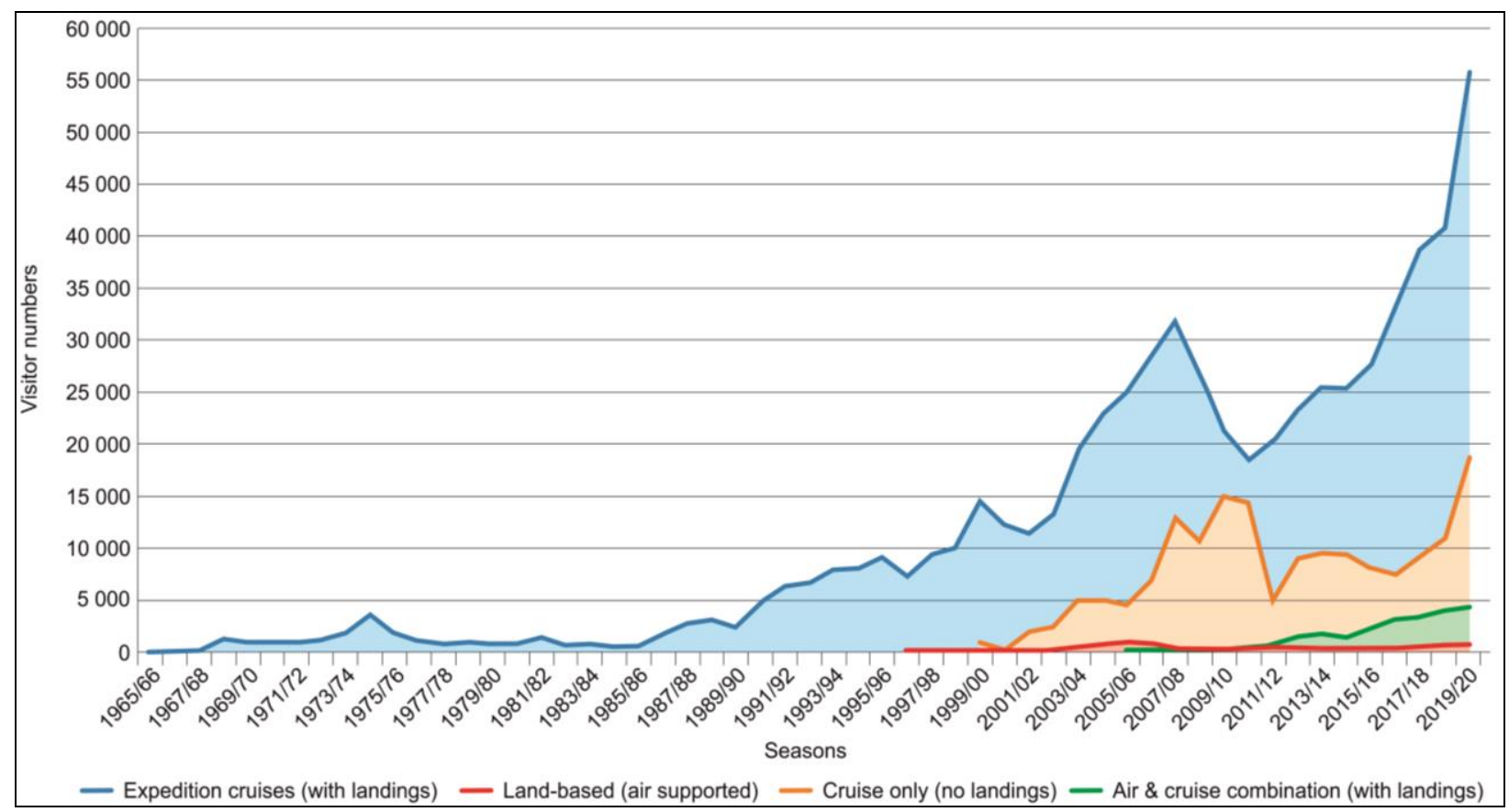

Figure 5. Tourists visiting Antarctica broken down to transport means 1965-2020 (Source: IAATO, 2019e; IAATO, 2020; supplemented)

Combined transport like 'fly-sail' and 'fly-cruise' contribute to the growing diversity of tourist operations. Typical operations involve flying tourists from South America to the Antarctic Peninsula and taking them back by ship, thus avoiding a double crossing of the stormy Drake's Passage and reducing travel time by 2-3 days. Other excursions offer, for example, sightseeing flights with no landing. They usually start and end in Australia (Hobart, Melbourne or Perth). Antarctica is no longer a privileged destination for tourists, as was the case at the beginning of the nineties of the twentieth century (Schmidt. 2007). The number and variety of offers provides a wide range of travelling options to a growing number of clients.

\section{Places most often visited}

Most visits involve travel by ship for an expedition with or without a landing. Landings require agreeable navigation and ice conditions. Other decisive factors in visiting a location is the presence of wild animals like penguins or seals, unrivalled landscapes, remains of cultural heritage such as whaling stations, discoverers' huts or old science stations. Modern research stations also belong to great attractions. (Lamers, 2009). Tourists reach land on board Zodiac type pneumatic boats, each taking up to 12 passengers on board. Once on land, tourists visit specific sites in small groups. Visits last merely one to two hours, however, the entire visit may last several hours depending on the 
number of passengers transported to land and back to ship. While at the early stage of Antarctic tourism, visits were limited to several locations on South Shetland Islands and the west coast of Antarctic Peninsula, today the total number of locations in the region reads 360 (IAATO, 2019d). Those most popular were visited from 100 to over 170 times per season They were visited by between 18 thousand to 24 thousand tourists (Table 4). These locations include Goudier Island, Cuverville Island, Neko Harbor, Whalers Bay, Half Moon Island, Brown Station and Danco Island. One of the icon landing locations is the old British 'Base A' in Port Lockroy on the Goudier Island, which in summer months is a 'live museum' with a souvenir shop and post office. However, not all locations are visited every season (Hughes and Davis, 1995).

Table 4. Top Twenty Most Visited Sites During the 2018-2019 Season (including yacht visits) (Source: IAATO, 2019d, p 6.)

\begin{tabular}{|c|l|c|c|}
\hline Rank & \multicolumn{1}{|c|}{ Landing Site } & Number of Landed Visits & Number of Landed Tourists \\
\hline 1 & Goudier Island & 172 & 18048 \\
\hline 2 & Cuverville Island & 160 & 22180 \\
\hline 3 & Neko Harbor & 157 & 18167 \\
\hline 4 & Whalers Bay & 149 & 18298 \\
\hline 5 & Half Moon Island & 131 & 17960 \\
\hline 6 & Brown Station & 121 & 70123 \\
\hline 7 & Danco Island & 107 & 9229 \\
\hline 8 & Jougla Point & 95 & 12698 \\
\hline 9 & Mikkelsen Harbor (D Hainaut) & 89 & 11259 \\
\hline 10 & Damoy Point/Dorian Bay & 84 & 8249 \\
\hline 11 & Telefon Bay & 71 & 7910 \\
\hline 12 & Portal Point & 63 & 8375 \\
\hline 13 & Orne Harbor & 58 & 5811 \\
\hline 14 & Brown Bluff & 56 & 6658 \\
\hline 15 & Petermann Island & 55 & 4824 \\
\hline 16 & Yankee Harbor & 53 & 7826 \\
\hline 17 & Port Charcot & 48 & 5895 \\
\hline 18 & Waterboat Point/Gonzalez VIdela Station & 44 & 3358 \\
\hline 19 & Aitcho Islands-Barrientos Island & 42 & \\
\hline 20 & Vernadsky Station & 42 & \\
\hline
\end{tabular}

The growing number of visitors to the peninsula results from introducing bigger cruisers carrying more than 150 passengers, a nd improved ship technology. New landing spots appear along Antarctic coasts particularly in the south around the Ross Sea, and in the northwest along Weddell Sea. In the Antarctic aviation tourist sector, sightseeing flights and flights over the area enjoy the longest tradition. By the end of the seventies of the twentieth century, Air New Zealand flew over 10 thousand passengers over Antarctica.

After the interval caused by the tragic aviation catastrophe on the slopes of Mount Erebus in 1979, interest in aviation tou rism gained on popularity in mid nineties. Today, two tour operators provide commercial flights to Antarctica. One is seated in Australia (Croydon Travel jointly with Qantas), and the other, Aerovias DAP Airlines, provide flights to Antarctica departing from Punta A renas in Chilli. The season 2017-2018 showed 3.4 thousand tourists enjoying this form of tourism (IAATO members only), (Tourism and NonGovernmental Activities, 2012; Antarctic Flights, 2020).

Table 5. Programs and Participant Numbers for 2018-19 season (Source: IAATO, 2019c, p.6.)

\begin{tabular}{|l|c|}
\hline \multicolumn{1}{|c|}{ Program } & No. Participating \\
\hline Emperor Penguin Colony Visits & 142 \\
\hline Deep Field Experiences (Camping, skiing, mountaineering, skydiving, cycling, etc.) & 44 \\
\hline Deep Field Flights (e.g. to Pole of Inaccessibility) & 17 \\
\hline South Pole Fly-in & 172 \\
\hline South Pole Ski Expedition & 14 \\
\hline South Pole Motorised Expedition & 22 \\
\hline Last 1-2 Degree Expedition & 43 \\
\hline Antarctic Crossing & 3 \\
\hline Vinson Massif & 148 \\
\hline Marathon & 110 \\
\hline
\end{tabular}

Another type of aviation services concern deep-field tourism. Tourists fly to the Antarctic Plateau in the inner part of the Antarctic continent. They next exercise extreme sports, hiking and skiing, mountaineering, marathon races, etc. (Table 5).

The number of deep-field tourists increased from nearly 600 in 2017/18 to 731 in the 2019/20 season.

\section{Future development of Antarctic tourism}

A visit to Antarctica is often a key event in life that changes people who associate with its least degraded natural environment. This effect exerts pressure on excursion organisers and tourists to keep Antarctica clean. Cruisers offer a package deal of transport, bread and aboard. No construction of permanent tourist facilities is required. Projections indicate that the present ship model tourism will persist. Best evidence of the above is the launching of nine new ice-strengthened passenger vessels (Greg Mortimer, Hanseatic Inspiration, Hanseatic Nature, Hondius, Magellan Explorer, Roald Amundsen, Scenic Eclipse, Silver Whisperer and World Explorer) in 2019-20, all of which will operate in the Peninsula area. The new vessels reflects an investment in new tonnage, predominantly by companies that have been operating in Antarctica for decades, following the finalisation of the IMO's International Code for Ships Operating in Polar Waters (IAATO, 2019c).

The development of tourism inland is strictly linked with access to runways. It is probable that aviation tourism related infrastructure in Antarctica will develop. Many locations already upgrade their runways today. Perhaps large passenger planes will fly over Drake's Passage to an upgraded landing strip on King George Island, where tourists can board awaiting excursion vessels. This may open the option to develop tourism southwards along the western coast of the Antarctic Peninsula to reach earlier inaccessible places. Such a development will increase the potential detrimental impact on the environment and may give rise to restrictions in the number of accepted guests. 


\section{CONCLUSIONS}

Antarctic tourist figures in the last decade showed a growing trend. In the 2018-19 season, the figures reached over 55 thousand, and over 70 thousand visitors in 2019-2020. Antarctic tourism is extremely seasonal and is concentrated in several accessible regions featuring unique environmental and historic assets. In general, they involve less than $0.5 \%$ of ice-free land of the continent, especially around the Antarctic Peninsula. One of the most important contemporary challenges facing Antarctica, in view of the study results presented in the article, is effective planning of tourism development and comprehensive tourist traffic control. The excessive, massive and uncontrolled development of tourism may in the future cause irreversible harm to the environment. Due to the above, the monitoring of the tourist phenomenon is vital for studies of the continent. The developments in Antarctic tourism and the related uncertainties regarding potential cumulative impacts may require, now or in the near future, the adoption of restrictions to Antarctic tourism activities to prevent irreversible damage in the future (Bastmeijer and Roura, 2004).

Antarctic tourism is today's best managed tourism sector in the world and encourages other sites to adopt the solutions applied in Antarctica. The bounding Antarctic Treaty is devoted to protection of the environment and science. Time will show whether the Antarctic Treaty system and IAATO activity manage to deal with future changes in this dynamically developing sector (Stonehouse and Crosbie, 1995).

Education is a vital issue of the visits to Antarctica thanks to IAATO activity. It provides an opportunity to become acquainted with this exceptional continent and its merit for world science. The experienced voyage helps to understand better the objective, need and responsibility of tourism, and the protection of the continent. Guests travelling with IAATO representing over 100 varied nationalities become the ambassadors of Antarctica on returning home. They are usually well educated and influential. Probably, they will remain open to the issue of protecting the continent, having experienced the educational atmosphere on board ships, which are fundamental for Antarctic tourism. The planned development assumed growth at the present level to figures over 100 thousand in the 2024/25 season. However, due to the pandemics, which slowed down tourism worldwide, including Antarctic tourism, this date will shift considerably forward in time.

\section{REFERENCES}

Bastmeijer, K., \& Roura, R. (2004). Regulating Antarctic Tourism and the Precautionary Principle. The American Journal of International Law, 98(4), 763781. https://doi.org/10.2307/3216699

Cavallo, E.M. (2019). An Assessment of the Environmental Regulatory Framework Regarding Increasing Tourism Activity in Antarctica. World Maritime University. Malmö, Sweden.

Engelbertz, S., Liggett, D., \& Steel, G. (2015). Values underlying the management of ship-borne tourism in the Antarctic Treaty area. The Polar Journal, 5(2), 334-360. https://doi.org/10.1080/2154896X.2015.1080492

Enzenbacher, D.J. (1993). Tourists in Antarctica: numbers, and trends. Tourism Management, 14(2), 142-146. https://doi.org/10.1016/0261-5177(93)90048-P

Haase, D., Storey, B., McIntosh, A., Carr, A., \& Gilbert, N. (2007). Stakeholder perspectives on regulatory aspects of Antarctic tourism. Tourism in Marine Environments, 4(2, 3), 167-183. https://doi.org/10.3727/154427307784771959

Haase, D., Lamers M., Storey, B., \& Amelung B. (2009). Heading into uncharted territory? Exploring the institutional robustness of self-regulation in the Antarctic tourism sector. Journal of Sustainable Tourism, 17(4), 411-430. https://doi.org/10.1080/09669580802495717

Headland, R.K. (2009). A chronology of Antarctic exploration: a synopsis of events and activities from the earliest times until the International Polar Years, 2007-09. Bernard Quaritch Ltd, London. https://doi.org/10.1017/S0032247409008535

Hughes, J., \& Davis, B. (1995). The management of tourism at historic sites and monuments. in Hal, C.M. \& Johnston, M., E. (eds.), Polar tourism: Tourism in the Arctic and Antarctic regions. Chichester, John Wiley and Sons, 235-255.

Johnston, M.E. (1997). Polar tourism regulation strategies: Controlling visitors through codes of conduct and legislation. Polar Record, 33(184), 13-20. https://doi.org/10.1017/S0032247400014121

Lamers, M. (2009). The Future of Tourism in Antarctica - Challenges for Sustainability. Retrieved from Universitaire Pers Maastricht: https://cris. maastrichtuniversity.nl, accessed 21 May 2020.

Landau, D., \& Splettstoesser, J. (2007). Management of Tourism in the Marine Environment of Antarctica: The IAATO Perspective. Tourism in Marine Environments 4(2-3), 185-193.

Liggett, D., \& Storey B. (2007). Stakeholder perspectives on Regulatory Aspects of Antarctic Tourism. Tourism in Marine Environments 4(2-3), 167-183. https://doi.org/10.3727/154427307784771959

Liggett, D. (2015). Destination Icy Wilderness. in Liggett, D., Storey B.,Cook,Y., Meduna V.eds. Exploring the last Continent, An Introduction to Antarctica, Springer International Publishing Switzerland, 379-388. https://doi.org/10.1007/978-3-319-18947-5

Molenaar, E.J. (2005). Sea-Borne Tourism in Antarctica: Avenues for Further Intergovernmental Regulation. International Journal for Marine and Coastal Law, 20(2), 247-295.

Neumann, A. (2020). Wilderness Protection in Polar Regions - Arctic Lessons learnt for the Regulation and Management of Tourism in the Antarctic. The University of the Arctic (UArctic), Published by Brill, 71-183.

Schmidt, O. (2007). Nachhaltigkeit des Antarktistourismus. Sustainability of Antarctic Tourism. Seereisen Magazin, 4(17), accessed 20.06.2019. https://www.seereisenmagazin.de/jahrgang2007/Ausgabe-4-2007/017-antark tis-special-2.htm

Snyder, J.M., \& Stonehouse, B. (2007). Prospects for polar tourism. CABI, Eds. Cromwell Press, United Kingdom.

Splettstoesser, J. (2000). IAATO's Stewardship of the Antarctic environment: A history of tour operator's concern for a vulnerable part of the world. International Journal of Tourism Research, 2, 47-55. https://doi.org/10.1002/(SICI01522-1970(200001/02:13.0.CO;2-7

Splettstoesser, J., Landau, D., \& Headland, R.K. (2004). Tourism in the forbidden lands: The Antarctica experience. in T.V. Singh (Ed.), New horizons in tourism. Strange experiences and stranger practices, Cambridge, MA: CABI Publishing, 27-36.

Stewart, E.J., Draper, D., \& Johnston, M.E. (2010). A Review of Tourism Research in the Polar Regions. Arctic, 58(4), 383-394. https://doi.10.14430/arctic452

Stonehouse, B., \& Crosbie, K. (1995). Tourist impacts and management in the Antarctic Peninsula area. in Hall, C. M., Johnston, M. E. (Ed.), Polar tourism: tourism in the Arctic and Antarctic regions, John Wiley and Sons, 217-233.

*** Antarctic Flights (2020). accessed 20 May 2020. http://www.antarcticaflights.com.au

*** Antarctic Tourism - Human Impacts, Threats and to Environment, (2020). accessed 10 May 2020. http://www.coolantarctica.com

*** Antarctic Station Catalogue (2017). The Council of Managers of National Antarctic Programs. Christchurch, New Zealand.

*** IAATO (2018). Report on IAATO Operator Use of Antarctic Peninsula Landing Sites and ATCM Visitor Site Guidelines, 2017-2018 Season, IP 72, XLI Antarctic Treaty Consultative Meeting, Buenos Aires. Argentina, 13-18 May.

*** IAATO (2019a). Catalogue of IATTO Operator Activites. IP 145, 2-5.

*** IAATO (2019b). Education \& Outreach by IAATO - an update for 2019. IP 98, XLII Antarctic Treaty Consultative Meeting, Prague, Czech Republic, 1-5.

*** IAATO (2019c). Overview of Antarctic Tourism: 2018-19 Season and Preliminary Estimates for 2019-20, Season, IP 140, 1, 1-30.

*** IAATO (2019d). Report on IAATO Operator Use of Antarctic Peninsula Landing Sites and ATCM Visitor Site Guidelines, $2018-2019$ Season, IP 142, 6.

*** IAATO (2019e). Tourism in Antarctica, 2019. accessed 27.09. 2020. www.iaato.org

*** IAATO (2020). IAATO Antarctic visitor figures 2019-2020, accessed 229.09. 2020. www.iaato.org

*** Tourism and Non-Governmental Activities in the Antarctic: Environmental Aspects and Impacts. (2012). CEP Tourism Study, May, 6-78. 